\title{
Review of the Wood Industry in Kenya; Technology Development, Challenges and Opportunities
}

\author{
George Muthike*, Joseph Githiomi \\ National Forest Products Research Programme, Kenya Forestry Research Institute (KEFRI),Nairobi, KENYA. \\ *Corresponding Author: Dr. George Muthike, National Forest Products Research Programme, \\ KenyaForestry Research Institute (KEFRI), Nairobi, KENYA.
}

\begin{abstract}
Forests worldwide have significant economic, environmental, social and cultural values. Kenya forest sector is vibrant, undergoing a number of remarkable changes. It is estimated that the forestry sector contributes approximately 3.6\% of the country's gross domestic product (GDP). The sector contributes in excess of KSH 20 billion (about 180 MillionEuro) annually worth of goods to the economy (KFS 2014). Forestry sector in Kenya is fairly supported by relevant policies and programmes geared towards sustainable management and aligning the sector to the country's vision and aspirations for the future. The creation of the National Forestry Programme (NFP) has revitalised the coordination of the sector, with private forestry emerging as a source for employment and wealth creation. The sector is however faced by numerous challenges to include and not limited to: inadequate forest sector funding, which impacts on possibilities to implement strategic policies like NFP; inadequate capacity of the County Governments to implement devolved forestry functions like overseeing management and utilization of the forest resource on community and private land and weak organizational framework to adequately support on-farm tree growing. Although re-vitalizing, the wood industry is struggling with technological challenges with a considerable number of inefficient processing systems, gaps in technical as well as businessmanagement skills to run wood processing business. Variations in rain patterns presumably due to climate change poses major setbacks in the development of forestry and forest products particularly in Arid and Semi-arid Lands (ASaLs).
\end{abstract}

\section{BACKGROUND}

Forest sector continues to support livelihoods in Kenyan, providing forest-related goods and services. The Kenya Green Economy Strategy Implementation Plan 2015 (GoK, 2015) STATES THAT NATURAL RESOURSE-BASED SECTORS CONTRIBUTE ABOUT 42\% OF THE COUNTRY'S GDP. It's most significant contributions are in energy for industrial processes and domestic use. Other major uses include timber for building and construction as well as environmental services such as regulation of water flows, local climate conditions and provision of carbon reservoirs and sinks (Githiomiet al., 2012). The forest cover in Kenya declined during the period 1990-2000 from 7.98 to about $2.3 \%$, but has now taken an upwad trend, due to improved afforestation activities and is projected to reach about $7.5 \%$ in 2018 (KFS, 2013).

Loss in forest cover is highly attributed to among others, conversion of forest land to other uses. This is necessitated by the country's growing human population both in the rural and urban settlements (KFS, 2013). Consequently, the supply of forest products among them biomass energy, timber and non-timber forest products is far below the current demand (MENR, 2005). In 2012 the demand for round wood, was 41.7 million $\mathrm{m}^{3}$ with a corresponding supply of 31.4 million $\mathrm{m}^{3}$, leaving a deficit of 10.3 million $\mathrm{m}^{3}$. This situation is expected to continue with a deficit of 15 million $\mathrm{m}^{3}$ projected by 2032(MEW\&NR, 2013). While most of the wood processed in particularly large industries is primarily from state forests, private farms and communal lands, mainly in the Arid and Semi-Arid Lands (ASALS) provide over $90 \%$ of the total wood supplies in these areas, most of it being used for fuel (MEW\&NR, 2013).

The contribution of forests towards economic, environmental, social and cultural values in Kenya cannot be underrated (ADB, 2007; Gatsby Foundation, 2016). It is estimated that the forestry sector contributes well over 20 billion Kenya shillings annually worth of goods to the economy, which is approximately $3.6 \%$ of the country's gross domestic product (GDP) (KFS 2014). Forests and forest product support other major sectors of the economy including building and construction, energy, 
agriculture, livestock, wildlife, water, fisheries, tourism and trade, thus cumulatively contributing to between 33\% and 39\% of GDP (MEW\&NR, 2013).

Timber processing, especially from plantation forests plays a major role in the country's development (Republic of Kenya, 2016). In Kenya, sawmilling provide employment to many people in forested rural areas(Muthike, 2016).During the 1999-2011 ban that locked out the wood industries from state forests, wood supplies to most wood based industries got reduced, culminating in closure of most of the timber industries, particularly those in the Small and Medium Enterprise (SME) category. As a result, socio-economic development was adversely affected due to reduced employment opportunities especially in areas where the local economies depended on the industry (Muthike et al., 2010). It also resulted in an acute shortage of timber products, prompting increase in wood and wood products imports from neighbouring countries. Consequently, cross-border timber trade, both legal and illegal sprung, making timber trade a major challenge in the region (Samuel et al., 2007).

Farm forestry sub-sector contributes substantially to the growth of Kenya's economy as it does in other countries (Pasiecznik, 2010). With natural forests being increasingly protected for the 'global good' and forest plantations having to compete with agriculture for limited space in state and communal land, trees growing on farms continue to be an important supplement (World Agro forestry Centre, 2004). In Kenya for example, during the ban, in an effort to sustain their operations, a few wood processing industries turned to farms as supplemental source of logs. This however became uneconomical due to increased distances to the tree source, decreasing volumes, cost of collecting few logs from farm to farm and decreased log quality. Local sawyers, using small-scale movable sawing systems took up the operations on farms to provide the highly needed sawn timber (Holding et al., 2001; Holding-Anyonge \& Roshetko, 2003). However, most of these sawing systems have been shown to be inefficient, thus contributing to deforestation (Muthikeet al., 2010).

In the absence of such efforts, outside traditional forest zones like in farms and dry lands, wood from unprocessed trees provide relatively little income when sold for fuel, posts or unprocessed logs. In some areas, studies on the sawn timber value chain indicated that tree owners get as little as $10 \%$ of the sawn timber value when they sell the trees unprocessed (Muhumuza et al., 2007). Sawing logs onsite therefore remain a favourable option and increases value and revenues to the tree farmers, encouraging them to plant more (Muthike et al., 2010). This also promotes local economies by providing raw materials for local needs and employment for the local population, who serve as saw operators and others along the value chain (Samuel et al., 2007).

On the farm, three movable sawing systems; bench, chain and pit saws are used (Pasiecznik, 2010; Muthike et al., 2010). Bench saw machines are common in areas where wood is available in relatively large quantities and easily accessible. Pit saws were used in very remote areas, especially where trees grow in steep terrains limiting access by bench machines. Due to the introduction of chainsaws, pit saws have become almost irrelevant. Chainsaws, although not initially designed for sawing dimensioned timber, have been adopted because they generally require relatively lower initial investment than bench saws and are faster than pit saws. They have been used in areas that are not easily accessible by conventional saw milling or the movable bench saw equipment (Pasiecznik and Brewer, 2006; Marfo, 2010). Their efficiency is relatively low compared to the other movable alternatives (Muthike et al., 2013).

In Kenya and a number of other countries particularly in Africa, chainsaws have constantly replaced the other systems and have become the dominant sawing system, particularly on farms (Muthike et. al., 2008; Marfo, 2010). Over the years, chainsaw system has become widespread as means for producing timber in small volumes from isolated trees and trees in difficult terrain as well as deformed logs. The sawing practice has evolved as a major source of livelihood for small-scale operators, farmers and the rural communities (Pasiecznik, 2010). These sawing systems involve less invasive equipment than conventional saw milling. They involve manual labour instead of mechanised skidders, while small hand-held machines are used instead of large heavy duty fixed mills (Wit et. al., 2010).

\section{Forest POLICY IN KENYA}

The Sustainable Development Goals (SDG) call for significantly mobilisation of resources from all sources and at all levels to finance sustainable forest management (SFM), and provide adequate incentives to developing countries, to promote forest conservation (MENR, 2005). Kenya's Vision 2030 provides the country's overall sustainable development framework (GoK, 2007). The overall 
objective of the vision is to transform Kenya into a middle-income country, providing a high quality life to all citizens by the year 2030. It is therefore the key reference point for the country's macro and micro-economic development planning. The vision calls for effective management of forests in view of the envisaged development in order to ensure sustainability and the attainment of Constitutional threshold of $10 \%$ forest cover.

At the international and regional level, Kenya has affirmed its commitment to SFM by signing several Multilateral Environmental Agreements (MEAs) and the East Africa Community (EAC) Treaty and associated Protocols, policies and strategies. In line with these, several policies targeting the attainment of $10 \%$ forest cover have been formulated. These include the The Forests Act, 2005, the Agriculture (Farm Forestry) Rules, 2009 and the draft National Energy Policy, 2014. While forestry supports agriculture, agriculture relies on land for food security and its expansion has negative impacts on forestry (MENR), 2016). The National Food and Nutrition Security Policy, 2011 therefore lays emphasis on strategies aimed at enabling local communities to effectively adapt to climate change and reduce impact on food and nutrition security. Realisation of the objectives of these strategies in view of limited land and therefore competition for land uses requires more focus to be placed on enhancing land productivity, raw material conservation and efficient processing and utilization of natural resources. The vision 2030 therefore further gives attention to efficient wood based industrial development.

\section{Management of Forest Resources}

There are numerous actors and stakeholders in forestry and forest industry sectors in Kenya. The Ministry of Environment and Natural Resources (MENR) is the parent Ministry providing policy guidance and oversight in governance of environment and natural resources. The establishment of the National Forest Programme has gone a long way in coordinating the various actors in the sector for efficient work (MENR, 2016).Various state bodies under the Ministry of Environment and Natural Resources play their respective roles based on their specific mandates. Kenya Forest Service (KFS)is a semi-autonomous corporate body with a mandate to enhance development, conservation and management of Kenya's forest resource base in all public forests. KFS has the management responsibility of state forest plantations as well as the protection of gazetted indigenous forests. Furthermore, KFS is responsible for assisting County Governments to develop and manage forest resources on community and private lands through advisory services. Other ministries have supplementary roles depending on their specific interests connected to forestry and/or natural resources.

County Governments are responsible for some of the functions of the forestry sector devolved from the National Government. Gazette Supplement No.116 of 9th of August 2014 specifies forestry functions to the County Governments. The devolved functions include forest advisory and extension services, creation of an enabling environment for forest enterprise development and funding of Sustainable Forest Management (SFM) models, especially on community and county government lands. Others include forests and game reserves formerly managed by Local Authorities, excluding forests managed by KFS, Kenya Water Tower Agency (KWTA) and private forests.

\section{FORESTRY RESEARCH AND DEVELOPMENT}

Research plays an important role in the development, management, conservation and utilization of forests and forest products. Kenya Forestry Research Institute (KEFRI) is a cooperate institution, whose mandate is to conduct research in forestry and allied natural resources. KEFRI undertakes research in forestry in four thematic areas: Forest Productivity and Improvement; Biodiversity and Environmental Management; Forest Products Development and Socio-economics, Policy and Governance. Each of these thematic area is headed by a deputy director. Regional programmes implement the different thematic mandates in their respective climatic regions of the country. The Forest Products Development thematic area cuts across all the other themes, spearheading forest products development, utilization and marketing. This is implemented through the National Forest Products Research Programme (NFPRP).This programme has the mandate to develop technologies for processing and utilization of timber and non-timber forest products. The information and technologies generated through research is disseminated to the public in appropriate packages including but not limited to production and processing guidelines, policy briefs and guidelines, 
technology operation guidelines, research notes as well as conference and peer reviewed journal publications. KFS, forest industries and tree farmers are major consumers of these information packages. KEFRI also offers consultancy and advisory services to the forestry sector and the industry.

\section{FOREST SYSTEMS IN KENYA}

\subsection{General Overview}

The bulk of forests in Kenya are natural forests. Most of the natural forests (about 3.3 million ha) are owned and/or managed by communities, most of them being woodland-type forests in the Arid and Semi-Arid Lands (ASaLs) (IUCN, 2001). Natural forests in higher rainfall areas are typically public gazetted forests, managed by KFS. The natural forests are important for hosts for wildlife, as water catchment and regulators and as source of wood energy. Over $80 \%$ of Kenya's energy requirements come from wood and the main source is the ASAL woodlands (Githiomi et al., 2012). Available statistics indicate that a total of about 232,300 hectares of forest plantations are established the country. There is some substantial area under farm grown trees.

\subsection{Plantation Forestry}

The major part of the forest area (about 60\%) in Kenya is state plantations managed by KFS. These form a total of 149,922 ha located mainly in Rift Valley and Central regions of Kenya. The rest are mainly small scale industrial plantations owned by tea companies and wood lots privately owned by individual farmers. However, there is no reliable information available on the total extent of forests owned by individuals due to lack of structured data base (KFS, 2012).

At the moment, establishment of forest plantations is mainly carried out by communities neighbouring forest stations. This is done through Plantation Establishment through Livelihood Improvement Systems (PELIS), which is a contractual arrangement between Community Forest Associations (CFAs) and KFS. In addition, in some areas, the wood industry players participate through voluntary monetary and labour contributions towards seedling production and planting. Silvicultural treatment (pruning and thinning) is carried out by KFS labour and to some extent by CFAs. Wood from thinning and clear felling is sold on stumpage to the wood industry, based on short-term allocations to prequalified industry operators. Wood harvesting from plantations is guided by the national allowable cut computations, which is updated annually through the forest management and felling plans. Timber harvesting has however steadily increased since the lifting of the logging ban and is currently around 1.5 million $\mathrm{m}^{3}$ (KFS, 2013).

\subsubsection{Challenges}

The period of the ban $(1999$ - 2011), posed more than a decade of minimal management inputs into forests and low harvesting. As a result, the quality and stocking levels of stands were affected. Currently, plantation forests are not optimally distributed due to a large gap between over mature and very young plantations. In addition, there has been inadequate silvicultural operations leading to prevalence of pests, diseases and rot in wood. With a steady increase in demand for round wood from the expanding industry, there is already a general decline in supply of mature round wood for specialised uses like plywood making. This is likely to increase and affect other uses like sawn timber due to the skewed tree population distribution (IUCN, 2001).

Considering forest productivity and quality, the recently introduced PELIS may pose some risks in plantation establishment through intercropping. The farmers could give more attention to the agricultural crops than the trees being established. This could result in poor establishment and growth in some young plantations and hence low quality wood for industrial use at maturity. To mitigate these risks, the system needs high level of supervision, specifications on the type of crops to be intercropped with tree seedlings and close monitoring. Lack of adequate resources and inadequate modalities for monitoring as well as weak CFAs have already been reported as contributing to the poor performance of PELIS in some areas. In other areas, management of post-PELIS stands is inadequate, with low levels of pruning, thinning and use of out-dated methods and equipment.

\subsubsection{Opportunities}

There are opportunities for improvement in productivity and sustainable economic returns from forestry. PELIS system can help in fast establishment of forest plantations. If well managed, it can provide low cost care for seedlings to healthy stands, while providing livelihoods for the farmers. The 
system can be scaled up and enhanced through community involvement in silvi cultural activities beyond PELIS. This will however require strengthening capacities of the responsible institutions. The CFAs need to be engaged more in training their members and developing capacities among the people engaged as well as taking the CFA involvement into consideration when developing management methods. There is also need to further refine roles and responsibilities between KFS and other public and private sector partners, emphasising their respective roles and synergy in forest development and management. There are potential gains in developing wood harvesting and processing methods that capture the true value and lead to optimum economic utilization of the available wood. Investment in efficient wood harvesting and processing technologies is a necessary consideration during this period of growing shortage and demand for industrial round wood.

\subsection{Farm Forestry}

There is little information available on the current extent of farm forestry in Kenya. However, tree growing on farms has been on-going all over Kenya. A major driver for tree growing on farms is income from sales of trees. Like in many other countries, farmers in Kenya look at their plantations as a "bank" to be utilized when income is needed (Muthike, 2016; Pasiezcnik, 2010). Eucalyptus and Grevillea species are by far the most common tree species grown on farms in Kenya. The underlying factors for preference of these species include the current growing demand for Eucalyptus power transmission poles and shorter rotation period of 7-12 years for a variety of end products compared to over 20 years for Pinus and Cupressus species.

Tree growing on farms take different patterns depending on the available land. Farmers with less than 2 ha of farm land tend to grow trees along the borders while those with more land establish wood lots and plantations. Intercropping trees with crops during the first 3 years is typical in many areas in Kenya. A study by World Bank in 1980's, gave an indication that there is potential in farms to supplement state forest land for tree growing. More work by Githiomi et al, (2012) indicated that more fuel wood was being sourced from farms that state forest plantations. This shows that tree growing on farms has gained importance, with support being acquired from various local and international organizations. There also exist numerous associations and groups of tree growers at community level, many of them under the Farm Forestry Smallholder Producers Association of Kenya (FF-SPAK) which is an umbrella organisation for local tree growers' associations. So far FFSPAK has been carrying out capacity building interventions to its members. There is also the Kenya Forest Growers Association (KEFGA), established in 2008 and has about 300 members with trees ranging from small scale wood lots to large-scale forests of more than $200 \mathrm{ha}$.

In addition, various actors and support groups have found space in Kenya's farm forestry. The German Ministry of Agriculture is at the moment starting up support to some tree growers in Kericho and Nakuru counties. Gatsby Foundation is at its initial phase of its "Kenya Commercial Forestry Programme" in June 2016 which focuses on improving tree seeds, plantation establishment and marketing of wood products. The programme is working with both small-scale farmers and industrial plantations through Kenya Tea Development Agency (KTDA). KOMAZA, a social enterprise established in 2006 is also supporting tree growing and marketing in the dry and coastal areas of the country. At the moment the company has engaged with about 6000 farmers that have so far established around 2000 ha of small scale woodlots of Eucalyptus and/or Meliavolkensiii species (KOMAZA, 2016). Trees grown under support and advice from the enterprise are owned by the enterprise with farmers providing inputs in form of land and labour and receiving income when the trees are sold. The company is planning to establish its own wood processing facilities in future.

\subsubsection{Challenges}

Farm forestry in Kenya is generally hampered by low quality germplasm as well as weaknesses in establishment and management of trees for industrial use. This is mainly due to inadequate capacity and knowledge among farmers, who are more conversant with crops than trees (Pascieznik et al., 2006). Private tree growers in Kenya are typically passive players in forestry and wood market. They rarely would seek advice from foresters om the way to grow trees for a particular end product, thus at maturity, most of the trees lack placement in the market. Many farmers with trees wait to be approached by interested traders and lack skills in valuation of the trees as well as marketing. For example, some years back Eucalyptus growing was triggered by a high demand for power 
transmission poles. Due to abundant planting, imports and introduction of concrete poles, there is currently an over-supply of poles. As a result, tree growers have challenges in selling their Eucalyptus as transmission poles and prices have fallen sharply, prompting search for alternative uses, which many farmers are unable to do.

The sawn timber and wood panel industry predominantly source their wood from state plantations. Due to supply from private farms being small volumes, lower quality and with logistical challenges, there is generally no interest in sourcing from private farms. Instead private tree growers have to engage with small processors like chainsaw and mobile bench operators to process their trees. This results in lower recovery and low quality of the sawn timber (Muthike et al., 2013). Many of the tree farmers lack skills and capacity to recognize inefficient processing and poor quality end product when they have their trees processed by the operators. Similarly, many of the small-scale processing operators don't put emphasis on efficient processing since they are paid based on quantity and not quality of the timber from the trees they process.

\subsubsection{Opportunities}

Demand for wood products (fuel wood, sawn timber, wood panels, pulp \& paper) is ever growing in Kenya. Through proper tree management and efficient processing efforts, this can be translated to income for private tree farmers. Furthermore, there are indications that supply of wood from state plantations may not adequately satisfy the growing demand in the near future. Through proper interventions, private tree growers can be well positioned to address supply shortages and increase their earnings from the farms.

\subsection{The Forest Industry and Utilization of Forest Resource}

The largest volume of round wood from plantations in Kenya goes to sawn timber and wood composites. Until the year 2011, the wood composite sector was dominated by a few big producers. Lately, Small and Medium Enterprise (SMEs) producers investing in processing equipment have emerged. One of the main driving forces behind the investments is the increased cost of round wood from state plantations, hence the need for higher recovery of the available raw material into higher value. With the only round wood using pulp and paper mill closed since 2009 , now been revived, its demand for raw materials will impact on supply to the growing number of SME wood processors.

The sawmilling industry is now re-vitalizing and moving towards more efficient processing. Many are investing in horizontal band saws, moving away from the earlier circular saws. According to KFS reclassification in May 2016 there are about 29 sawmills classified as large with sawn timber production of over $20 \mathrm{~m}^{3} /$ day and 175 sawmills classified as medium scale with sawn timber production $10-20$ $\mathrm{m}^{3} /$ per day. All these saw mills rely on state plantations for their round wood supply. Very little is sourced from private plantations, mainly due to volumes, quality and logistical challenges.

Some wood is used as industrial and domestic fuel wood by especially tea factories and households in rural areas respectively. Although most of the tea factories rely heavily on wood from farms while others grow their own wood lots and small plantations, substantial supplies come from the forest plantations, especially the Eucalyptus species.

\subsubsection{Challenges}

Although the sawmilling industry is undergoing re-vitalization, there is still a big number of sawmills using old and in-efficient technology. The bulk of existing sawmills (473 of the 677 classified sawmills by KFS) is still small units with sawn timber production of less than $5 \mathrm{~m}^{3}$ per day. To optimize on efficiency in resource utilization, there is a need for revitalization of the sub-sector. Investment in new technology seem to have led to a gap in capacity and technical skills to run the sawmills. There are also indications of weaknesses in business and management skills.

At the moment, majority of sawn timber is produced without seasoning and/or grading. This results in low quality products down streamas well as inefficient application of sawn timber in construction industry due to over-dimensioning to compensate for inferior quality. Post sawing handling of timber needs to be in cooperated in the industry. Before the ban, timber grading courses were conducted by the sector players (KEFRI, KFS, MOPW, KBS and timber industry). Revival of this course could go a long way in offering a solution to the challenges of over designing of timber structures. There is need to promote integrated timber processing in particularly the SME sector for higher value addition. 


\subsubsection{Opportunities}

The ever increasing demand for wood products presents good opportunities for enterprise development and employment creation by strengthening the SME wood industry. This can be done through awareness and promotion activities as well as entrepreneurship facilitation. Vocational training will play important role in developing technical work force in the sector. Proper engagement of farm forestry as suppliers of wood can mitigate the impacts of shortage in wood supply from state plantations. Dry areas can be matched with appropriate tree species to provide additional supply of round wood in the future. There are indications that there is a growing awareness and preparedness to pay more for better quality sawn timber. This can be built upon and further promoted through among others value addition procedures like timber seasoning and grading and secondary processing.

The on-going re-vitalization of the industry provides for good opportunities for training. Vocational training may become a very important part of the operations in the sector. During the logging ban, KTMA lost momentum and also importance among its members. Now, when industry is growing and modernizing, there is definitely room for an industry professional association to be in the centre for lobbying, coordination and awareness creation. Curricular needs to be developed geared towards answering some of the skill-based challenges that the industry is facing at the moment.

\section{THE WAY FORWARD}

Sound management of forests involving private sector can lead to improved forest productivity, increased employment and improved livelihoods. A more efficient management may be achieved through Private-Public Partnership arrangements with private sector, taking a more emphasized role in short term management of plantations.Improved forest products and marketing can also be achieved on farms through better competencies among farmers and processors, resulting in improved quality of round wood and value added products coming out from farms.

Revitalization of sawmilling industry has continued with increasing number of wood industries coming into the sector using different processing systems. Research should be continued to develop data on wood intake capacities and timber recovery rates for various categories of wood industries in the sector. This would assist the Government in optimizing the allocation of the available wood materials based on need for the industry. In addition, Kenya Forestry Research Institute (KEFRI) and other stake holders need to provide information on the currently used logging practices and develop technologies for enhancing wood recovery during logging.

\section{ACNKOWLEDGEMENTS}

This study was facilitated by Kenya Forestry Research Institute through the Government of Kenya Research Funds. The authors wish therefore to appreciate the support and timely delivery of necessary resources by the Director KEFRI.

\section{REFERENCES}

[1] ADB (African Development Bank), 2007. African Development Report 2007. http://www.afdb.org/en/ knowledge/publications/african-development-report/african-development-report-2007/

[2] George Muthike, 2016. Opptimization of on-farm machine design parameters for efficient timber sawing based on empirical approach. Jomo Kenyatta University of Agriculture and Technology. PhD Thesis.

[3] Githiomi J. K., Mugendi D. N. and Kung'u J. B., 2012.Analysis of household energy sources and wood fuelutilisation technologies in Kiambu, Thika and Maragwa districts of Central Kenya. Journal of Horticulture and Forestry Vol. 4(2), pp.43-48, 1 February, 2012.

[4] GoK (2007). Kenya Vision 2030.Government of the Republic of Kenya. Nairobi.

[5] Holding-Anyonge C, Roshetko JM (2003). Farm-level timber production: Orienting market. Unaslyva 212 9540:48-56.

[6] Holding C., P. Njuguna and C. Gatundu. 2001. Farm sourced timber: the restructuring Kenya. Opportunities and challenges. Forest Extension, IUFRO, Vienna, Austria.

[7] Gatsby Foundation, 2016. Overview of the Kenya Commercial Forestry Programme

[8] IUCN Eastern Africa programme, 2001. Economic Aspects of Community Involvement in Sustainable Forest Management in Eastern and Southern Africa

[9] KFS (Kenya Forest Service), 2012. Draft Strategy for the Development of the Kenya Estate Plantation Forests. MMMB, KFS. 
[10] KFS (Kenya Forest Service), 2013.Report on National Forest Resource Mapping and Capacity Development for the Republic of Kenya.

[11] KFS(Kenya Forest Service), 2014. Kenya Forest Service Strategic Plan: 2014-2017.

[12] KOMAZA, 2016.Review of Governance of the Forest Sector in Kenya. MitiMingi Maisha Bora Programme. LTSI, 2016: Presentations on web page.

[13] Marfo, 2010. Chainsaw milling in Ghana: Context, drivers and impacts. (in), Wit, Marieke and Jinke van Dam (eds.). (2010). Chainsaw milling: supplier to local markets. European Tropical Forest Research Net work. Tropenbos International, Wageningen, the Netherlands, pp. 22-226.

[14] MENR (Ministry of Environment and Natural Resources). 2005. The Forest Act 2005. Government Printers, Nairobi: MENR.

[15] MEWNR (Ministry of Environment, Water and Natural Resources), 2013: Analysis of Demand and Supply of Wood Products in Kenya. Ministry of Environment, Water and Natural resources. Government of Kenya.

[16] Ministry of Environment and Natural Resources, 2016. National Forest Programme 2016 - 2030. MENR, Nairobi, Kenya.

[17] Muhumuza, F., S. Kutegeka and A. Wolimbwa. 2007. Wealth Distribution, Poverty and Timber Governance in Uganda: A Case Study of Budongo Forest Reserve. ACODE Policy Research Series, No. 26, 2007, Kampala.

[18] Muthike GM, Shitanda D, Kanali CL and Muisu FN, 2010.Chainsaw milling in Kenya. In; wit, marieke and Jinke van Dam (eds.), (2010). Chainsaw milling: supplier to local markets. European Tropical Forestry Research Network; Tropenbos international, wageningen, the netherlands. xxii $+226 \mathrm{pp}$.

[19] Muthike GM., Shitanda D, Kanali CL and Muisu FN., 2008. The potential of chainsaw frame mills in onfarm timber processing in Kenya. In; recent advances in forestry research for environmental conservation, improved livelihood and economic development. Proceedings of the fourth KEFRI Scientific Conference, October 6-9, 2008, Nairobi, Kenya.

[20] Pasiecznik NM and Brewer MCM (2006).Chainsaw milling, an appropriate technology to increase benefits from on-farm trees. Demonstration, poster and presentation. In: Benefits of Farm Woodlands and Agroforestry in UK Lowlands. Third Annual Meeting of the Farm Woodland Forum, 27-28 June 2006. Northmoor Trust, Oxford, UK.

[21] Republic of Kenya, 2016: Improving efficiency in forestry operations and forest product processing in Kenya. UN-REDD Programme.

[22] Samuel JH, Pasiecznik NM, Fehr C. 2007.The Potential of Chainsaw Milling Outside Forests. Summary report with economic and policy case studies from East Africa. HDRA, Coventry, UK.66pp. http:// chainsaw.gwork.org/.

[23] Wit, marieke and Jinke van Dam (eds.). (2010). Chainsaw milling: supplier to local markets. Tropenbos international, wageningen, the netherlands. xxii $+226 \mathrm{pp}$.

[24] World Agroforestry Centre, 2004. Small-holder Timber Workshop Notes. CD-ROM. Small-holder Timber Workshop, November 29-December 1, 2004, World Agroforestry Centre, Nairobi, Kenya.

Citation: G. Muthike, J. Githiomi, " Review of the Wood Industry in Kenya; Technology Development, Challenges and Opportunities ", International Journal of Research Studies in Agricultural Sciences (IJRSAS), vol. 3, no. 10, p. 8, 2017. http://dx.doi.org/10.20431/2454-6224.0310005

Copyright: (C) 2017 Authors. This is an open-access article distributed under the terms of the Creative Commons Attribution License, which permits unrestricted use, distribution, and reproduction in any medium, provided the original author and source are credited. 